\title{
Study of blood donor profile in a blood bank attached to a medical college hospital - a retrospective study
}

\author{
Nidhi Rajendra ${ }^{1}$, Prashanth Madapura $V^{2}$ \\ ${ }^{1}$ Dr. Nidhi Rajendra, Assistant Professor, Department of Pathology, Dr. B R Ambedkar Medical College and Research \\ Centre, KG Halli, Bangalore, Karnataka, India, ${ }^{2}$ Dr. Prashanth Madapura V, Assistant Professor, Department of \\ Paediatrics, M.S Ramaiah Medical College and Hospital, MSRIT Post, Bangalore, Karnataka, India.
}

Address for Correspondence: Dr. Nidhi Rajendra, \#27, Sir MV Layout, Vidyaranyapura Post, Bangalore, Karnataka. Email: rnidhi25@gmail.com,

\begin{abstract}
Background: Blood Transfusion Services (BTS) are the vital part of modern health care system without which efficient medical care is impossible. To make blood donation safe and increase the confidence of the masses in voluntary blood donation, many safety measures are implemented by the blood transfusion community. The most important of all safety measures is donor selection. Stringent, meticulous and serious donor screening is necessary to afford protection to blood donors and recipients. Aim \& Objectives: The aim of this study was to document the current rate and reasons for donor deferral in our tertiary care Centre. Materials and Methods: This retrospective record based study was carried out for whole blood donors at Dr. B R Ambedkar Medical College Hospital Blood bank. Results: In our study the majority of the registered donors were replacement donors (92.2\%). Total 2556 people registered for donating blood during the study period (5 years), of whom $2140(83.7 \%)$ were males. 176 donors were deferred by medical officer based on detailed medical history and brief physical examination of donors with regard to hemoglobin (Anaemia), blood pressure (hypertension), temperature (hyperthermia/fever), and pulse irregularity and rate. The majority of donors were deferred for temporary reasons (61.3\%) and others were permanently deferred. Conclusion: The donor deferral rates and reasons for deferral for blood donation are important issues to be highlighted among blood donors, general public, in the blood banks and hospitals. We can add a significant number of donors by recruiting back a large number of temporarily deferred donors by remotivating them after addressing the reason for deferral.
\end{abstract}

Keywords: Anaemia, Blood donor, Permanent deferral, Hypertension

\section{Introduction}

Blood Transfusion Services (BTS) is the vital part of modern health care system without which efficient medical care is impossible [1]. The main goal of blood transfusion services globally is to ensure the availability of safe and adequate supply of blood and blood products. It is estimated that donation by $1 \%$ of the population (10 per 1000 population) is generally the minimum needed to meet a nation's most basic requirements for blood; the requirements are higher in countries with more advanced health-care systems. National AIDS Control Organization's (NACO) statistics show that the annual rate of blood donation in

Manuscript received: $6^{\text {th }}$ November 2017

Reviewed: $16^{\text {th }}$ November 2017

Author Corrected: $24^{\text {th }}$ November 2017

Accepted for Publication: $30^{\text {th }}$ November 2017
India is about 7.4 million units, against the requirement of 10 million units. According to the WHO, over 81 million units of blood are collected annually worldwide, but only $39 \%$ are collected in developing countries, which have $82 \%$ of the world's population [2].

The paucity of healthy, safe blood donors has always been a serious problem for the blood banks worldwide. While it is important to ensure that there is an adequate supply of blood, it is also essential that the blood collection and transfusion process does not harm either the donor or the recipient [2].

According to the Drugs and Cosmetics Act, not every person who walks into a camp/blood bank for blood 


\section{Original Research Article}

donation is a donor. Donor by definition is a person who, after complete medical examination by the doctor, is declared fit for donation of blood. To make blood donation safe and increase the confidence of the masses in voluntary blood donation, many safety measures are implemented by the blood transfusion community. The most important of all safety measures is donor selection. Stringent, meticulous and serious donor screening is necessary to afford protection to blood donors and recipients [3].

Blood donors are deferred for various reasons. The rate and reasons of deferral differs from region to region and center to center. Individuals disqualified from donating blood are known as "deferred" donors [4].

Various causes of the pre-blood donation deferral need to be studied systematically to improve the donation rate. Deferral is a painful and sad experience for blood donor as well as the transfusion centre and it necessitates additional efforts towards new recruitments. Moreover, deferring prospective donors often leaves them with negative feelings about themselves as well as the blood donation process [5].

Hence detailed analysis of various causes for deferral of blood donors may help medical personnel and doctors to curb the barriers that impede the blood donation [6].

Methodology: Place and type of study: This is a retrospective record based study done at Dr.B $\mathrm{R}$
Ambedkar Medical College \& Hospital Blood Bank, Bengaluru.

Sampling methods: The blood donors data from January 2012 to December 2016 (5 years) was collected from blood bank registry at the study site were analysed.

Inclusion criteria: Donors who have donated blood at the outdoor voluntary blood donation camps as well as at the blood bank (indoor) were included in the study.

\section{Exclusion criteria}

1 . Voluntary donors $<18$ years and $>60$ years.

2. Pregnant women.

Standard operating Procedures based on the Directorate General of Health Services guidelines, Ministry of Health \& Family Welfare (2003) used for donor selection and deferral. Pre-donation screening tests like donor questionnaire followed by physical examination \& Haemoglobin estimation by $\mathrm{CuSO} 4$ (finger prick) method with cut off value of $12.5 \mathrm{gm} / \mathrm{dl}$ were done. Donors with systolic BP between $100 \& 150 \mathrm{~mm}$ of $\mathrm{Hg}$ and diastolic BP between 60 and $100 \mathrm{~mm}$ of $\mathrm{Hg}$ were accepted for blood donation. Deferred donor data was analyzed with respect to age, sex and causes of deferral (temporary and permanent). The different causes of deferrals in male and female blood donors were also analyzed.

Institutional Ethical Review Board permission was obtained and donor details were kept confidential.

\section{Results}

The study was done by collecting and analyzing the data of five years from 1st January 2012 to 31 st December 2016 in the blood bank. In our study most of the registered donors were replacement donors (92.2\%) and voluntary donors accounted for $7.7 \%$. Total 2556 people registered for donating blood during the study period, of whom $2140(83.7 \%)$ were males and 416(16.2\%) were females. 176 donors were deferred by medical officer based on detailed medical history and brief physical examination of donors with regard to hemoglobin, blood pressure, temperature, and pulse regularity and rate. Out of 176 deferred donors, 149 were males and 27 were females. Percentage of deferral among the total number of registered males and females were $(6.9 \%)$ and $(4.5 \%)$, respectively. Demographic profile of gender distribution of registered blood donors, selected and deferred donors is shown in Table 1.

Table-1: Gender distribution of registered, selected and deferred donors

\begin{tabular}{|c|c|c|c|}
\hline Donors & Male & Female & Total \\
\hline Registered & 2140 & 416 & 2556 \\
\hline Selected & 1991 & 389 & 2380 \\
\hline Deferred & 149 & 27 & 176 \\
\hline
\end{tabular}

In our study most of the deferred male donors were in the age group between 31-40 years, followed by 18-30 years and in females it was 18-30 years. 


\section{Original Research Article}

Table-2: Demographic profile of various age groups of deferred blood donors.

\begin{tabular}{|c|c|c|}
\hline Age in years & Number of male donors & Number of female donors \\
\hline $18-30$ & $38(25.5 \%)$ & $15(55.5 \%)$ \\
\hline $31-40$ & $49(32.8 \%)$ & $08(29.6 \%)$ \\
\hline $41-50$ & $34(22.8 \%)$ & $03(1.1 \%)$ \\
\hline $51-60$ & $28(18.7 \%)$ & $01(3.7 \%)$ \\
\hline Total & $\mathbf{1 4 9}$ & $\mathbf{2 7}$ \\
\hline
\end{tabular}

The majority of donors were deferred for temporary reasons $(61.3 \%)$ and smaller subset i.e. 68 (38.6\%) donors were permanently deferred.

The causes for deferrals in the temporary and permanent subsets are shown in Table $3 \& 4$ respectively. Anaemia $(\mathrm{Hb}<12.5 \mathrm{gm})$ was the leading cause of donor rejection $(25 \%)$ followed by medication history $(21.2 \%)$ amongst temporary causes. In permanently deferred category, Hypertension was the most common cause constituting $85.2 \%$ of all the permanently rejected potential donors.

Table-3: Temporary causes for donor rejection.

\begin{tabular}{|c|c|}
\hline Temporary causes for rejection & Number of cases \\
\hline Low haemoglobin & $27(25 \%)$ \\
\hline History of medication & $23(21.2 \%)$ \\
\hline Under weight & $05(4.6 \%)$ \\
\hline Low blood pressure & $16(14.8 \%)$ \\
\hline Tattooing & $12(11.1 \%)$ \\
\hline Previous blood donation & $11(10.1 \%)$ \\
\hline History of alcohol & $04(3.7 \%)$ \\
\hline Menstruation & $05(4.6 \%)$ \\
\hline Vaccination history & $02(1.8 \%)$ \\
\hline Previous hospitalization & $03(2.7 \%)$ \\
\hline
\end{tabular}

Table-4: Permanent causes for donor rejection

\begin{tabular}{|c|c|}
\hline Permanent causes of deferral & Number of cases \\
\hline High blood pressure & $58(85.2 \%)$ \\
\hline Age & $03(4.4 \%)$ \\
\hline High risk factors & $05(7.3 \%)$ \\
\hline Epilepsy & $02(2.9 \%)$ \\
\hline
\end{tabular}

The five leading causes of deferrals in males and females is explained in Table 5. In males it is hypertension and in females low hemoglobin is the most common cause among five leading causes for deferral in blood donors.

Table- 5: Five leading causes of deferral in males and females

\begin{tabular}{|c|c|c|c|}
\hline \multicolumn{2}{|c|}{ Males } & \multicolumn{2}{c|}{ Females } \\
\hline Causes & Number of cases & Causes & Number of cases \\
\hline High blood pressure & 58 & Low hemoglobin & 07 \\
\hline History of medication & 17 & Listory of medication & 06 \\
\hline Low hemoglobin & 20 & Menstruation & 05 \\
\hline Tattooing & 12 & Under weight & 03 \\
\hline
\end{tabular}




\section{Original Research Article}

\section{Discussion}

Transfusion of blood and blood products is of utmost importance, where blood transfusion is done in emergency to save the life of patients. While blood donation is very much an essential requirement for time, still this blood donation process should not harm donor and with that maintain safety of recipient as well [7]. Safe donor selection is the first step towards safe transfusion services [3]. Predonation selection of the donor is done for the safety of both donor and the recipient. Most important is the selection of blood donors by donor selection criteria. A large number of blood donors are not able to donate blood successfully for several reasons, either temporarily or permanently [7].

National and international efforts are on to ensure safe blood supply through screening, education and strict criteria laid down by the Directorate General of Health Sciences, Ministry of Health and Family Welfare (2003) and Eligibility criteria for blood donation American Red Cross [3]. In this study, various reasons for deferral from blood donation have been studied. In our study most of the donors were men $(83.7 \%)$ when compared to women $(16.2 \%)$. This finding was similar to various other studies. Nanik jethani et al reported $95.89 \%$ male and $4.1 \%$ female donors, Birjandi reported $95.6 \%$ male and $4.4 \%$ female donors and Unnikrishnan et al. reported $95.13 \%$ male and $4.8 \%$ female donors. $[2,9,10]$. The low female donor population can be attributed to ignorance, fear, lack of awareness and motivation among females.

It was noticed that the replacement donation (92.2\%) was significantly higher than the voluntary donation $(7.7 \%)$ in our study. This is due to less outdoor voluntary donation camp during our study period. The incidence of deferral rate in our study was $6.8 \%$. The deferral rate was almost same in males $(6.9 \%)$ and females $(6.4 \%)$. Our study results were similar to the studies done by $\mathrm{P}$ Sundar, Müller-Steinhardt $\mathrm{M}$ and $\mathrm{Y}$ Rabeya which reported deferral rates of $6 \%, 6.2 \%$ and $5.6 \%$ respectively $[11,12,13]$. The lowest reported rate of rejection was reported by Talonu $\mathrm{T}$ as $4 \%$ in Papua New Guinea.[14]. Higher rates from 8-15\% were reported by Chaudhry, Lim, Blumberg and Ranveet $[15,16,17,18]$. The rate of deferral differs from region to region and sometimes in the same region from one center to another [8]. However, the international comparison shows that the deferral rates reported as
$6.2 \%, 10.8 \%, 12.8-15.6 \%, 14 \%, 14.4 \%, 14.6 \%, 5.8-$ $16.4 \%$ and $16 \%$ in Germany, France, USA, Japan, Singapore, Turkey, India and Nigeria respectively $[12,19,20,21,16,22,23,24]$. On the basis of age group in our study, most of the male deferral donors were seen in $31-40$ years $(32.8 \%)$ and females donors in $18-30$ years (55.5\%). Other Studies done by various authors observed maximum deferrals in the age group (both sex) of 18-30 years.[1,3,25,26]. In our study there were $68(38.6 \%)$ permanent deferrals as against $108(61.3 \%)$ temporary deferrals. similar studies done by Preethi BA et al. reported $73.8 \%$ temporary and $26.2 \%$ permanent donors, Rateesh S reported $82.71 \%$ temporary and $17.29 \%$ permanent donors and Custer et al. reported $68.5 \%$ temporary and $31.5 \%$ permanent deferrals $[4,6,17]$.

The lower numbers of permanent deferrals in our study are due to the majority of young donors. In our study low hemoglobin 27 cases $(25 \%)$ which leads to anemia is being reported as the main cause of temporary deferral in males and females followed by medication history 23 cases $(21.2 \%)$. Low hemoglobin was the commonest cause of deferral in most of studies by Sundar et al, Charles et al. and Agnihotri N. [11,27,28]. The minimum cut-off hemoglobin level for blood donation is $>12.5 \mathrm{gm} \%$ irrespective of sex. In many studies it is observed that the most common cause for deferral is anemia, even in western studies. In Canada, $2 \%$ of all blood donors do not meet minimum hemoglobin standard, whereas in developing countries the number is more as pointed by this study (more than $21 \%$ ) [29]. In a study by Halperin et al, the three most common short term temporary deferral are low hemoglobin level, colds and/or sore throats, and elevated temperature, whereas that by Ranveet et al, under-weight, under-age, and low hemoglobin levels $[18,30]$. Hence, studies on donor deferral indicate that in each region there would be unique sets of reasons.

The effect of short-term, temporary deferral (STTD) on blood donor returns and subsequent blood donation is an important issue. STTD have a very negative impact on blood donor return rates and subsequent donations [30]. The primary cause of permanent deferral was hyper-tension $(70.7 \%)$. Bahadur et al. and Shah et al. also reported hypertension as the leading cause of permanent deferral [23,25]. It was surprising that hypertension, along with cardiac problems, was roughly 


\section{Original Research Article}

equally distributed in various age groups. In younger age groups, this might be due to apprehension and anxiety for donation, induced by fear of phlebotomy or fear of the sight of blood. Hypertension is a growing, undiagnosed, epidemic in our country, where people seek medical advice on appearance of signs and symptoms, and seldom go for annual checkups. Additionally, use of electronic blood pressure equipment, with more objective readings could have picked up more hypertensive donors.

\section{Conclusion}

The donor deferral rates and reasons for deferral for blood donation are important issues to be highlighted among blood donors, general public, in the blood banks and hospitals. With the motivation of new donors, we can add a significant number of donors by recruiting back a large number of temporarily deferred donors by remotivating them after addressing the reason for deferral.

The permanent deferrals should be insighted for the illness and to be managed accordingly. Studying the profile of blood donors could help to identify sections of the population which could be targeted to increase the pool of voluntary blood donors and also to guide and provide the necessary essential database for the policy design and programme implementation. Women who are medically fit should be motivated for blood donation. Annual routine health checkup and screening for illness and anemia should be recommended for the general public to reduce deferral rates during blood donation.

Author contributions: Dr Nidhi Rajendra, corresponding author collected, analyzed and interpreted the data.

Dr Prashanth MV, Co author contributed for the design of the study, preparing and critically reviewing the manuscript.

Acknowledgement: I acknowledge the support of Blood Bank Officer and staff of Blood Bank, Dr BR Ambedkar Medical College Hospital, Bangalore.

\section{What this study adds?}

Five most common causes for donor deferrals is defined in our study.

Funding: Nil, Conflict of interest: None initiated, Permission from IRB: Yes

\section{References}

1. H Gajjar, F R Shah, N R Shah, C K Shah. Whole blood donor deferral analysis at General hospital blood bank - A retrospective study. NHL Journal of Medical Sciences 2014;3(2):72-76

2. Nanik J, Vinit G, Geeta P, Shruti A, Neena K, G Ali. Analysis of predonation blood donor deferral characteristics in Ajmer (Rajasthan) region. International Journal of Medical Science and Public Health 2016;5(12):2436-42

3. Rateesh S, Gajendra N G, Akanksha D. Donor awareness: Key to successful voluntary blood donation. 16 Oct 2012. doi: 1 10.12688/f1000research.1-29

4. Preeti B A, Divyesh G, Sajjan S S, Sujanani S. Predonation Deferral of Blood Donors in Tertiary Care Hospital Attached to Medical College in Southern Rajasthan. J Pharm Biomed Sci 2016;06(07):460-463.

5. Girish C.J., ChandrasheKhar T.N., Ramesh B.K., KanTiKar SM. Pre-Donation Deferral of Whole Blood Donors in District Transfusion Centre. Journal of Clinical and Diagnostic Research 2012;6(1): 47-50

6. M Vimal, S Sowmya, A Nishanthi and G Ramya. Evaluation of Blood Donor Deferral Causes: A Retrospective Study from South India. Annals of Pathology and Laboratory Medicine 2016; 3 (6):605-11.

7. Amit S, Prarthana J, Grishama B A, Kamlesh J S. A study on analysis of blood donation deferral during blood donation camp at tertiary-care teaching hospital in south Gujarat region. International Journal of Medical Science and Public Health 2016;5(5): 894-97.

8. Krishna M C, Sharada.M S, Harish S G, Raman M H. An Analysis of Pre-Donation Deferral of Blood Donors in a Teritiary Care Teaching Hospital Blood Bank Unit, Tumkur, Karnataka, India. International Journal of Healthcare Sciences 2014;2(2):258-62.

9. Birjandi F, Gharehbaghian A, Delavari A, Rezaie N, Maghsudlu M. Blood donor deferral pattern in Iran. Arch Iran Med. 2013 Nov;16(11):657-60. doi: 0131611 / AIM.009.

10. Unnikrishnan B, Rao P, Kumar N, Ganti S, Prasad $\mathrm{R}$, Amarnath A. Profile of blood donors and reasons for deferral in coastal South India. Australas Med J 2011;4(7):379-85 


\section{Original Research Article}

11. Sundar P, Sangeetha SK, Seema DM, Marimuthu P, Shivanna N. Predonation deferral of blood donors in South Indian set-up: An analysis. Asian J Transfusion Sc. 2010; 4(2):112-15

12. Müller-Steinhardt M, Weidmann C, Wiesneth $M$, et al. Donor deferral rates after the implementation of a New German blood donor questionnaire. Transfus Med Hemother. 2012;39(1):17-22. doi: 10.1159/000335581

13. Rabeya Y, Rapiaah M, Rosline H, Ahmed SA, Zaidah WA, Roshan TM. Blood pre-donation deferralsa teaching hospital experience. Southeast Asian J Trop Med Public Health. 2008;39(3):571-4

14. Talonu T. Causes of volunteer blood donor rejection in Papua New Guinea. P N G Med J. 1983 Sep-Dec;26 (3-4):195-7.

15. Chaudhary RK, Gupta D, Gupta RK. Analysis of donor-deferral pattern in a voluntary blood donor population. Transfusion Med. 1995;5(3):209-12.

16. Lim JC, Tien SL, Ong YW. Main causes of predonation deferral of prospective blood donors in the Singapore Blood Transfusion Service. Ann Acad Med Singapore. 1993 May;22(3):326-31.

17. Custer B, Johnson ES, Sullivan SD, Hazlet TK, Ramsey SD, Hirschler NV, Murphy EL, Busch MP. Quantifying losses to the donated blood supply due to donor deferral and miscollection. Transfusion. 2004 Oct; 44 (10):1417-26.

18. Ranveet K, Sabita B, Neelam M. A Reappraisal of under lying causes in donor deferral. Ann Natl Acad Med Sci. 2002;38:93-9.

19. Lawson-Ayayi S, Salmi LR. Epidemiology of blood collection in France. Eur J Epidemiol. 1999 Mar; 15(3): 285-92.

20. Shaz BH, James AB, Hillyer KL, Schreiber GB, Hillyer CD. Demographic patterns of blood donors and donations in a large metropolitan area. J Natl Med Assoc. 2011 Apr;103(4):351-7

21. Ngoma AM, Goto A, Sawamura Y, Nollet KE, Ohto $\mathrm{H}$, Yasumura S. Analysis of blood donor deferral in
Japan: characteristics and reasons. Transfus Apher Sci. 2013;49(3):655-60. doi: 10.1016/j.transci.2013.06.020. Epub 2013 Jul 26.

22. Gülen H, Tüzün F, Ayhan Y, Erbay A, Oztürk E, Inan $\mathrm{S}$, Vergin $\mathrm{C}$. The evaluation of blood donor deferral causes. Pediatr Hematol Oncol. 2006 Mar;23 (2): 91-4.

23. Bahadur S, Jain S, Goel RK, Pahuja S, Jain M. Analysis of blood donor deferral characteristics in Delhi, India. Southeast Asian J Trop Med Public Health. 2009;40(5):1087-91.

24. Ekwere TA, Ino-Ekanem M, Motilewa OO, et al. Pattern of blood donor deferral in a tertiary hospital, south-south, Nigeria: A three-year study review. Int J Blood Transfus Immunohematol. 2014;4:7-13. DOI: 10. 5348/ijbti-2014-14-OA-2

25. Shah SD, Shah MC, Bhatnagar NM, Gajjar MD, Soni SA, Patel TA. Analysis of blood donor deferral characteristics in a tertiary care hospital in a blood bank-a review. SEAJCRR 2013;2(5):389-95.

26. Rathod K, Gupta M, Shah M. Analysis of blood donor deferral characteristics in a blood bank at a tertiary care hospital attached to medical college Gujarat. Biennial J GAPM. 2012;4(2):85-8.

27. Charles KS, Hughes P, Gadd R, et al.: Evaluation of blood donor deferral causes in the Trinidad and Tobago National Blood Transfusion Service. Transfus Med. 2010; 20(1):11-14.

28. Agnihotri N: Whole blood donor deferral analysis at a centre in Western India. Asian J Transfus Sci. 2010; 4 (2):116-22.

29. Ali AM, Goldsmith CH, McAvoy AT, Ali MA, Blajchman MA. A prospective study evaluating the lowering of hemoglobin standards for blood donors. Transfusion. 1989;29(3):268-72.

30. Halperin D, Baetens J, Newman B. The effect of short-term, temporary deferral on future blood donation. Transfusion. 1998 Feb;38(2):181-3.

\section{How to cite this article?}

Nidhi Rajendra, Prashanth Madapura V. Study of blood donor profile in a blood bank attached to a medical college hospital - a retrospective study. Pathology Update: Trop J Path Micro 2017;3(4): 406-411.doi:10.17511/jopm.2017.i4.08. 